\title{
TRES ACERCAMIENTOS CRISTIANOS AL PENSAMIENTO DE NIETZSCHE: WELTE, VATTIMO Y GONZÁLEZ DE CARDEDAL
}

\author{
Juan Manuel Medrano Ezquerro \\ Universidad de La Rioja
}

RESUMEN: La relación del pensamiento del filósofo alemán Friedrich Nietzsche (1844-1900) con el cristianismo nunca ha dejado de ser polémica y controvertida. Desde los más abruptos anatemas lanzados contra el proclamador de la "muerte de Dios", a quien llegó a considerarse "castigado" con su locura por sus "blasfemias", hasta la templanza crítica de una filosofía y una teología cristianas que ya en la segunda mitad del siglo XX consideraron -frente a las tesis de Nietzsche incompatibles con la creencia cristiana, como su, al menos aparente, condena de la compasión y del amor al prójimo- las muchas ideas del filósofo alemán que brotaban de un suelo nutricio cristiano y de aquellas otras que podían impulsar una severa reflexión autocrítica de la forma en la que el cristianismo históricamente había debilitado su promesa "religiosa" del Reino para convertirse casi exclusivamente en una instancia moralizadora, entre otras cosas.

Tales propuestas abiertas a Nietzsche se han dado tanto desde instancias teológicas como filosóficas. En este artículo vamos a mostrar tres acercamientos a Nietzsche desde el cristianismo. El que nos proponen los teólogos Bernhard Welte y el español Olegario González de Cardedal hasta la propuesta de Gianni Vattimo de reinterpretar la muerte de Dios en un sentido liberador para un cristianismo revitalizado y libre.

Palabras clave: Cristianismo, muerte de Dios, voluntad existencial, Jesús de Nazaret, Pablo de Tarso, iglesia, eternidad, compasión, cáritas, religión, moral, final de la metafísica.

\section{THREE “CHRISTIAN" APPROACHES TO NIETZCHE'S THINKING}

ABSTRACT: The relationship between the thinking of the German philosopher Friedrich Nietzsche (1844-1900) and the Christianity has always been polemic and 
controversial. From the most abrupt anathemas launched by the proclaimer of "God's death", who has even been considered "punished" with his insanity due to his "blasphemies", to the critical temperance of the Christian philosophy and theologies. Although Nietzsche's ideas were incompatible with the Christian belief (as his, at least apparently, condemnation of compassion and love towards one's neighbor), during the second half of the twentieth century, the Christian philosophy valued German philospher's ideas which emerged from a Christian ground and which could encourage to a reflexion and self-criticism of the way by which the Christianity had historically weakened its "religious" promise of the Kingdom to become a mere moral authority, among other things.

Such proposals open to Nietzsche have appeared from both theology and philosophy authorities. In this article, we are going to present three approaches to Nietzsche from the Christianity. We will discuss the approaches proposed by the theologians Bernhard Welte and the Spanish Olegario González de Cardedal, and Gianni Vattimo's proposal to reinterpret God's death with a liberating sense for a revitalized and firm Christianity.

Keywords: Christianity, God's death, existential will, Jesus of Nazareth, Paul of Tarsus, church, eternity, compassion, caritas, religion, moral, end of metaphysics.

\section{Introducción}

Estos hombres serios, trabajadores, justos, de profundos sentimientos, que aún son cristianos de corazón: tienen la obligación de vivir, a modo de prueba, una vez por algún tiempo sin cristianismo, deben a su fe pasar una temporada de este modo "en el desierto" -sólo para adquirir el derecho de hablar cuando se discute si el cristianismo es necesario [...] No, vuestro cristianismo carece de peso hasta que no hayáis vivido durante años sin cristianismo: hasta que os hayáis alejado mucho de él. ¡No cuando la nostalgia os lleve de vuelta, sino el juicio basado en una rigurosa comparación, significará algo vuestro retorno!

Nietzsche, Aurora, \# 61

Después de la II Guerra Mundial, el proceso que conocemos como "desnazificación", al que concebimos fundamentalmente en términos ideológico-políticos, tuvo también sus aspectos filosóficos. Más allá de la intensa polémica sobre el pasado de Martin Heidegger -aún inconclusa-, una nueva generación filosófica, comandada como casi siempre por Francia, reivindicará la importancia, radicalidad y belleza de la obra de otro filósofo afectado por la polémica: Friedrich Nietzsche 
(1844-1900). Fue el caso de los Deleuze, Foucault, Derrida, Bataille, etc., que tuvieron su eco también en España algo más tarde (Savater, Trías, Sánchez Pascual, etc. $)^{1}$. Sin embargo, es necesario reconocer que años antes de la guerra, en plena República de Weimar e incluso en los años del nazismo, algunos pensadores -entre ellos varios judíos- habían producido algunas de las más lúcidas y vigentes interpretaciones del filósofo de la muerte de Dios.

Lo que sucedió en el campo filosófico, ocurrió de modo similar en el campo de la teología. Ésta experimentó un notable enriquecimiento epistemológico después de los años cuarenta, alejándose de los parámetros neoescolásticos, para implicarse -a raíz de las experiencias durísimas de la época de guerras y entreguerras- en una suerte de teología "existencial". La inteligencia creyente ya no podía obviar el enorme sacrificio personal, heroico ("samaritano") que muchísimos hombres y mujeres del campo del ateísmo habían padecido buscando una liberación del "mal", con un arrojo en favor de los demás que sólo tenía precedentes entre los propios mártires.

Es en esos contextos donde hay que entender el respeto -pese a la distancia teórica- que se labraron los mejores representantes del "humanismo ateo", como lo llamaba Henri de Lubac². Ello hizo mirar con otros ojos a los viejos demonios anticristianos, como Marx o como Nietzsche, sin ir más lejos.

En el caso de Nietzche -aunque ya lo mejor de la filosofía alemana de los años treinta había puesto de relieve los aspectos que acercaban al filósofo al cristianismo, sin olvidar los que lo alejaban, como es el caso de Karl Jaspers o Karl Löwith- toda una generación de teólogos de los años centrales del siglo, dominantemente alemanes o de lengua alemana (pero también franceses), cuyas posiciones filosóficas reciben la influencia del Heidegger de "Ser y Tiempo", afrontarán una reflexión sobre Nietzsche alejada de los tópicos anticristianos habituales, tratando de profundizar, con el utillaje conceptual de la fenomenología y el existencialismo, en los aspectos de disposición y ética nietzscheanos -su "voluntad de veracidad" cristiana- que más lo acercan a una actitud globalmente cristiana, a pesar de su abierto ateísmo. De ahí surgió esa pléyade de teólogos protestantes y católicos que recuperaron un cierto Nietzsche para el cristianismo: Biser, Benz, Welte, Pannenberg, Tillich, Barth, etc.

Para suerte del pensamiento español, como la influencia de esta generación de teólogos sobre algunos representantes de la mejor teología española, ya en sus años de formación europea en Francia o Alemania en los años 60, fue más que notable, hemos tenido una generación teológica fecunda y abierta a las corrientes europeas, que se ha traducido en una serie de teólogos, hoy ya bastante mayores, que han seguido -enriqueciéndola- esa estela interpretativa de sus homólogos europeos sobre la filosofía "materialista" europea, en general, y sobre, Nietzsche en particular. Por citar sólo algunos ejemplos, mencionemos a González Faus, Castillo, Jon Sobrino y Olegario González de Cardedal.

1. VV.AA. En favor de Nietzsche, Madrid, Taurus, 1972.

2. LUBAC H. de, El drama del humanismo ateo, Madrid, Encuentro, 2008. 
Hemos querido en este artículo aportar la interpretación que algunos teólogos de generaciones y ámbitos distintos y un filósofo italiano, próximo por confesión

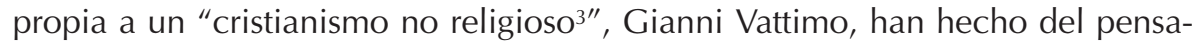
miento de Nietzsche, fundamentalmente alrededor de conceptos nodulares del filósofo como "voluntad de poder", "superhombre" y "muerte de Dios". Los tres pensadores vienen a coincidir en la existencia de una "actitud" ética de fondo cristiano, aunque haya atacado durísimamente el dogma, en Nietzsche y en las posibilidades que -queridas o no por el filósofo- se abren para el cristianismo más auténtico a raíz de los radicales cuestionamientos nietzscheanos sobre el "escándalo de la Cruz" o sobre la invasión de la fe cristiana por una mera moral.

En el caso de Vattimo, aún va más allá y señala cómo la muerte del Dios cristiano anunciada por Nietzsche, no concierne al Dios de Jesús, sino sólo al viejo "Dios de la metafísica" que impedía vivir libremente -asfixiado entre preceptos y conceptos- la ultima ratio de la actitud realmente cristiana ante la existencia: la caritas, el darse al "otro".

\section{La Teología. Los casos de Bernhard Welte y Olegario González de Cardedal}

Tanto en el ámbito de la teología protestante como en el de la católica, el impacto de las polémicas manifestaciones de Nietzsche ha sido profundo. Incluso casi podría resultar paradójico, a priori, que la inusitada agresividad que el pensador alemán muestra con el cristianismo no haya impedido la receptividad, a menudo teñida de comprensión, por parte de lo mejor de la teología del siglo XX. Veremos, analizando las posturas de algunos de ellos, las líneas fecundas que creen- abre Nietzsche al cristianismo.

Hemos descartado en este análisis las posturas extremas hacia su pensamiento evitando, por un lado, introducir la abundante reacción de hostilidad hacia el filósofo, común en las primeras décadas del siglo XX; del mismo modo, hemos dejado aparte aquellos casos -abundantes- de teólogos y pensadores cristianos que, al contrario que los anteriores, vieron en el análisis nietzscheano de la figura de Jesús y en su denuncia de una "invasión" de la religión por la moral, un rico y fecundo caudal de posibilidades para una, si no regeneración, si un replanteamiento de muchas de las tesis centrales del cristianismo.

En consecuencia, hemos preferido referir aquí el pensamiento de una teología templada ante las manifestaciones de Nietzsche; una teología que se da en el ámbito católico y protestante y en muchos de los mejores pensadores religiosos del siglo XX: desde Karl Barth a Lars Urs Von Balthasar, desde Pannenberg a Eugène Biser y que, en cierto modo, culmina en el jesuita francés Paul Valadier.

3. Este es precisamente el subtítulo de su obra Después de la cristiandad. Por un cristianismo no religioso, Barcelona, Paidós, 2003. 
¿Qué queremos decir con una teología templada a la hora de valorar la obra de Nietzsche? Sencillamente aquella que evita los extremos comentados, una teología receptiva pero crítica que, consciente de que existen afirmaciones (líneas rojas) en Nietzsche que un cristiano no puede traspasar por mucho que fuerce la interpretación ${ }^{4}$, ha encontrado sin embargo posibilidades fecundas de reflexión para los cristianos en los planteamientos de Nietzsche, sobre todo en relación con las siguientes cuestiones:

- El redescubrimiento de lo que significa el "escándalo" de la Cruz (en González de Cardedal, por ejemplo).

- La 'denuncia' de ciertas formas de ejercer el sacerdocio.

- Poner de nuevo en valor la verdad, belleza y dignidad de la Creación (Pannenberg).

- Encontrar en Nietzsche la misma aspiración íntima a la unidad y reconciliación de todo lo existente que forma parte de la esencia del cristianismo (Welte).

- La denuncia nietzscheana de una religión que se ha convertido en una pura "moral" (en Valadier o el mismo González de Cardedal).

\subsection{Bernhard Welte y la "voluntad existencial"}

Bernhard Welte (1906-1983) es uno de los pensadores católicos más importantes del siglo XX. Entre sus influencias cabe destacar el llamado "Círculo de Friburgo", del que fue miembro, Tomás de Aquino, Hegel, Nietzsche, Blondel, Jaspers y aún más notablemente Heidegger y el Maestro Eckhart $^{5}$. En este trabajo vamos a ocuparnos de un pequeño escrito de 1958 que dedicó a Nietzsche, a nues-

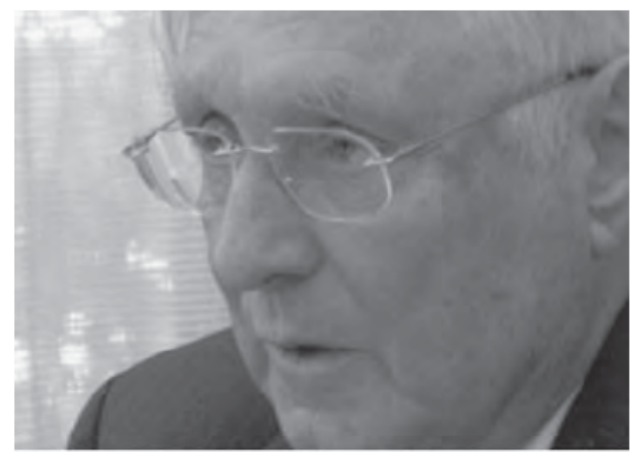
tro entender de importancia decisiva para un acercamiento al filósofo desde una perspectiva religiosa. La obra se titula El Ateísmo de Nietzsche y el Cristianismo ${ }^{6}$.

Welte no ignora la importancia de este pensador para el decurso de la posteridad ni cómo a pesar de las modas que se sucedían sobre su pensamiento-era

4. Sin profundizar en la cuestión parece más que evidente que ningún cristiano puede aceptar la desigualdad de los hombres ante Dios ni renunciar a la compasión en las relaciones humanas.

5. Para una reseña de la figura de Welte: W. AA. Filosofía cristiana en el pensamiento católico de los siglos XIX y XX, tomo III, Madrid, Ediciones Encuentro, 2003.

6. WELTE B. El ateísmo de Nietzsche y el Cristianismo, Madrid, Taurus, 1962. 
imposible mantenerse al margen del mismo. Desde el principio Welte acierta a situar la actitud a tomar respecto al pensador alemán:

La posición de los cristianos respecto a Nietzsche no va bien dirigida si se limita exclusiva y primariamente a la polémica de Nietzsche con lo que él entendía por cristianismo. [...] Como cristianos, hemos de atrevernos a intentar percibir y entender el decir positivo y real de Nietzsche, y no sólo sus acusaciones polémicas e injustas ${ }^{7}$

Se interroga Welte: ipor qué, pese a sus brutales frases y execraciones contra la religión cristiana, no se puede evitar una simpatía íntima, una reacción comprensiva, más emotiva que racional? ¿Qué hay en él que interpela a cada corazón, que habla de algo real en el interior del hombre?

La respuesta del teólogo es que Nietzsche anhelaba en el fondo de su ser algo que pertenece a la esencia del hombre, de todo hombre, y que Welte llama "voluntad existencial". El lenguaje en torno al concepto de "voluntad", que nos es familiar desde El mundo como voluntad y representación de Schopenhauer (del que Nietzsche nunca se desprende), es también el lenguaje elegido por Welte para examinar el hondo anhelo de unidad nietzscheano.

Todo hombre, todo ser, es depositario de algo que pertenece a su esencia, es una <voluntad>, una voluntad "existencial" Esa voluntad existencial es "aquello por lo cual el hombre quiere algo consigo mismo ya antes de que empíricamente quiera esto o aquello"8. Por tanto es una 'pulsión' o 'voluntad', una fuerza si se quiere, previa a su fijación sobre algo. Tal voluntad-continúa- es previa a todas las voliciones concretas, es un a priori de cualquier voluntad en manifestación.

Sería el descubrimiento de la muerte de Dios lo que aclara para Nietzsche el contenido de tal voluntad existencial. Tal voluntad, presente en todo hombre es la voluntad de ser:

Quiero ser es la voz más íntima de la existencia como aquí se la entiende, en toda congoja, en todo apartamiento, en toda desesperación y lo mismo en todos los triunfos existenciales ${ }^{9}$

Pero ese ser adquiere de inmediato la forma de poder. Ser como poder: ésta es la fórmula -sigue Welte- más íntima, más primordial de lo que es el hombre en cada momento. La voluntad más íntima del hombre, más allá de perseverar en el ser, es eliminar toda resistencia, todo límite, toda im-potencia. El ser-poder del hombre aspira a anular toda limitación, toda oposición; un ser-poder in-finito. Si Dios Ilegara a ser entendido -como sucedió en Nietzsche- como un poder

7. Ibíd., p. 11.

8. Ibíd., p. 24.

9. Ibíd., p. 26. 
"extraño", que limita al hombre, su desaparición puede ser deseada, como liberación del máximo límite que se ponía a los hombres. De ahí que el aforismo anterior al famoso 125 de La Gaya Ciencia se despliegue en metáforas de apertura, horizonte e ilimitación:

\begin{abstract}
¡Abandonamos la tierra y subimos a bordo! Hemos roto el puente que tras nosotros quedaba; más aún, hemos roto la tierra que dejábamos atrás. ¡Bien! Barquichuelo, ten cuidado. En torno tuyo no hay más que un océano; cierto es que no siempre brama, que a veces su sábana se extiende como si fuera de seda y oro, cual un ensueño de bondad. Pero vendrán horas en que tendrás que confesar que es infinito, y nada hay tan terrible como lo infinito ${ }^{10}$.
\end{abstract}

Bajo una fórmula brillante expresa Welte el anhelo nietzscheano: "la lucha de Nietzsche contra la moral tiene su origen en querer ser uno". Y la moral actúa contra la unidad, como una especie de contra-poder que divide al hombre. ${ }^{11}$

Sólo falta el pensamiento del eterno retorno para dotar de plenitud infinita a la vida y a toda la existencia que se quería efímera y limitada. El eterno retorno dota, según Welte, al ser (poder) de in-finitud e i-limitación; consagra la suprema afirmación de la existencia: "el instante debe tener la plenitud de la eternidad".

Y esa existencia en la unidad, plenitud e infinitud inocentes, no puede ser una vida fragmentada, ni una selección de lo mejor. El gran sí a la existencia debe ser un sí igual de rotundo e incluyente al dolor, al sufrimiento, a la muerte. Y la expresión para todo ello -en Nietzsche- no puede ser Cristo, sino Dioniso.

El pensamiento de Nietzsche es tal vez la creación más grande y la expresión más genuina de la voluntad existencial del hombre en los tiempos modernos, afirma Welte. Y si Nietzsche ha recurrido para expresar la máxima plenitud interior y vital del hombre a una imagen tomada de la religión, es porque la expresión de Nietzsche:

Quiero ser, en el fondo, viene a decir: quiero ser divino. Quiero ser Dios. Divino y Dios es mi interior imagen que me lleva a mi esencia y me dirige a ella ${ }^{12}$

Sin embargo, lo que en Nietzsche engarza con un pensamiento absolutamente tradicional en Occidente, que el hombre ha sido formado a imagen de Dios, tiene en él unas consecuencias completamente opuestas. Y aquí está el núcleo de la fuerza del ateísmo nietzscheano y del ateísmo moderno, como tam-

10. NIETZSCHE F., La Gaya Ciencia, Libro III, \# 124, p. 113-114.

11. WELTE, op. cit., p. 29. Recordemos como en demasiado humano I, \# 57, Nietzsche había dicho que "en la moral el hombre se comporta no como in-dividuum, sino como dividuum".

12. Ibíd., p. 36. 
bién señalaba Henri de Lubac: este ateísmo necesita la muerte de Dios, porque quiere ponerse él en su lugar: "Porque el hombre quiere ser Dios, no quiere que haya otro Dios", dice a su vez Welte ${ }^{13}$.

Welte quiere arrojar luz sobre esta contradicción: ¿cómo puede provenir esta lucha a muerte con la divinidad, y su feroz negación en la modernidad, precisamente de la raíz divina del hombre? Él advierte un desplazamiento: aunque cualquier forma de lo existente sólo puede ser objeto de deseo limitado, puesto que limitado es el bien ("lo limitado es lo nunca querido por completo"), puede ocurrir que la voluntad existencial más íntima del hombre aparezca desde su "apartamiento y penuria" precisamente como lo no querido. Y que esa voluntad, que esencialmente quiere lo infinito-divino como su más plena apetencia, apartada de su interioridad, desplace tal deseo de totalidad y de poder al ámbito impropio de su propia forma existencial-mundana, reclamado por lo que Welte Ilama el "esplendor de la proximidad y la actualidad de las posibilidades mundanas". La voluntad, dirigida ahora a un objeto "exterior", querrá eliminar por completo los restos de la vieja fe en Dios. Dicho en otros términos, si el hombre no es capaz de encontrar en su interioridad la presencia divina, que era lo que Jesús trataba de inculcar en quienes le escuchaban, puede querer encontrar esa potencia en su expresión exterior, como poder operante en la realidad. Lo que en una forma de interioridad podíamos Ilamar 'querer', querer infinito, que sólo se agota en su realización de poder como "servicio", puede transformarse, cuando pretende ejercerse en el mundo, precisamente en "dominación". Este parece ser el sentido en el que Camus interpreta las formas totalitarias en las que desemboca la rebelión moderna, bajo la fórmula de Dostoievski: "si Dios no existe todo está permitido ${ }^{14 "}$.

Esta contradicción desgarradora entre la aspiración más íntima y profunda al ser completo, al Uno, a lo indisociado, que frecuentemente resolvemos con el sustantivo "Dios" y la realidad de "tener que sufrir la contradicción de las relaciones de todo lo humano que siempre son sólo limitadas", carece de solución en la existencia humana. La consecuencia es una inquietud y una soledad que Nietzsche sufrió profundamente:

Este sufrimiento es el precio que ha de pagar la existencia en el impulso de querer tan grande y que a pesar de todo nunca quiere suprimir ${ }^{15}$

13. Ibíd., p. 37.

14. "Una vez derribado el trono de Dios, el rebelde reconocerá que esa justicia, ese orden, esa unidad que buscaba inútilmente en su condición tiene ahora que crearlos con sus propias manos y con ello deberá justificar la caída divina, Entonces comenzará un esfuerzo desesperado para fundar, al precio del crimen si es necesario, el imperio de los hombres. Esto no dejará de tener terribles consecuencias, sólo alguna de las cuales conocemos aún" (A. CAMUS EI hombre Rebelde, p. 45).

15. WELTE, 46-47. Palabras, éstas de Welte, muy próximas en intención a la condición desgarrada de la conciencia humana que -en opinión de Georges Bataille- el hombre trataba 
La otra posibilidad de romper esa inquietud es la fe en Dios, "el sí incondicionado". Pero, con buen criterio, advierte Welte, tampoco ésta es una solución terminante y definitiva. El hombre de la fe en Dios va a vivir, lo quiera o no, también la contradicción desgarradora entre su sí incondicionado al Creador y su realidad vital Ilena de limitaciones; realidad vital y carnal a la que a menudo denuesta precisamente como lo contrario y el enemigo de lo que cree su aspiración más absoluta. Los combates interiores de Pablo o Lutero son prueba de que esta contradicción disocia también al hombre de fe.

Por eso hay siempre algo en el hombre que tampoco quiere la fe, aun en aquél que quiere creer y que cree. Lo infinito querido en esta forma es también algo no querido a causa de la misma voluntad que está acuñada por ello para querer una plenitud indivisa y actual del ser.

Tampoco se resuelve el problema que es el hombre con la fe en Dios, como la otra consecuente gran posibilidad fundamental del querer. Nadie lo ha puesto de manifiesto con tanta firmeza en los tiempos modernos como precisamente Nietzsche ${ }^{16}$.

\section{El superhombre y la gracia}

Piensa finalmente Welte en una interpretación de la idea de "superhombre" diferente a las aberraciones que se han escrito sobre el asunto, no sin culpa también del propio Nietzsche. Lo genuino de la idea está en el sentido de por encima de. El hombre, como hombre, no puede solucionar la radical escisión que lo constituye, sea o no sea hombre de fe, tal como hemos apuntado. Aún menos puede formar parte de ese hombre superior forma alguna de violencia, que es manifestación nítida de división y por tanto de no-unidad del ser. Por eso, en última instancia, en Zaratustra la transformación definitiva es el "niño" y no el "león"17. El niño es la manifestación de "probidad de la existencia que ya no necesita luchar en sí contra lo inferior con violencia de ninguna clase"18.

Welte identifica ese impulso de Nietzsche hacia la superación del hombre en el mismo sentido de reconciliación de lo humano con lo divino a la que aspira el cristianismo auténtico. Y esto no puede darse en el hombre solo ni por sus

de superar con la fiesta: "La fiesta no es un verdadero retorno a la inmanencia, sino una conciliación desgarrada y llena de angustia entre necesidades incompatibles" (pág.. 59) Y: "El problema incesante planteado por la imposibilidad de ser humano sin ser una cosa y de escapar a los límites de las cosas sin volver al sueño animal recibe la solución limitada de la fiesta" (p. 57). Bataille, G., Teoría de la Religión, Madrid, Taurus, 1972.

16. Ibíd., p. 48.

17. NIETZSCHE F., Así habló Zaratustra, Libro I, "De las tres transformaciones".

18. WELTE, p. 55. 
propias fuerzas. En consecuencia -si comprendemos bien su mensaje del superhombre lo entenderemos como:

La única perfección posible de las relaciones humanas. Lo puramente sobrehumano hay que entenderlo entonces como la pura gracia. [...] Habla [Nietzsche] de lo que en la teología cristiana también se Ilama sobre-naturaleza. En este sentido, esta manera de hablar es con todo una manera cristiana, aun hablando como en embriaguez y locura19.

Sin duda Welte fuerza el acercamiento de Nietzsche a lo cristiano, al considerarlo como un "gran guía que tambaleándose, y sin saberlo, señala el mensaje de Jesús". Y es que, pese a todos los elementos paródicos o críticos que Zaratustra presenta frente al evangelio, el mensaje crucial de éste: "El reino está cerca" ${ }^{20} \mathrm{es}$ perfectamente tomado en serio por Nietzsche en su anhelo expectante del superhombre; y no habla en broma, sino desde una estructura mental y espiritual enclavada en el cristianismo cuando afirma que

Alguna vez, sin embargo, en una época más fuerte que este presente corrompido, que duda de sí mismo, tiene que venir a nosotros el hombre redentor, el hombre del gran amor y del gran desprecio... ${ }^{21}$

El mundo divino para Nietzsche, desde el Origen de la tragedia, es el mundo no escindido, es el mundo que haga retornar la in-dividuación traumática al seno de la unidad en la naturaleza: él lo llama Dionisos. Pero el fondo de salvaciónsuperación que late en la aspiración nietzscheana no dista -aunque sea a modo de un espejo invertido, en palabras de Welte- del anhelo cristiano:

La importancia de Nietzsche en el sentido de una inteligencia cristiana está en haber descubierto la tendencia que vive en la raíz de la humanidad a su salvación suprema ${ }^{22}$.

Por forzada que pueda parecer la interpretación de Nietzsche por Welte, hay elementos que nos hacen pensar en su plausibilidad, bien es cierto que la salvación nietzscheana, y la verdadera realización de la humanidad completa, el superhombre, es algo sólo específicamente posible en esta tierra y en esta vida. Trasladar esta realización, esta unidad de lo humano con lo divino, a otra existencia purificada, marca el umbral del entendimiento imposible. Pero Nietzsche no piensa en los términos en que habitualmente ha sido pensado el superhombre, en términos de diferencias jerárquicas o diferenciaciones aún peores. Nietzsche encontraba demasiado parecidos todavía al más grande y al más pequeño

19. Ibíd., p. 60-61.

20. Mc 1,15 .

21. NIETZSCHE F., La Genealogía de la Moral, Tratado II, \# 24.

22. WELTE, p. 64. 
de los hombres. Trasladados los términos de la superación-salvación del hombre a los contenidos en la vida estrictamente físico-espiritual, la estructura de su pensamiento está marcada por ritmos y jalones propiamente cristianos.

Nietzsche puede ser tratado, según me parece, como el testigo espiritual más grande del tiempo moderno, por el hecho de que la presencia ausente del poder infinito de Dios constituye realmente la esencia del hombre, pero testigo también porque siglos de la historia humana han hecho arraigar y condensarse esa ausencia. No son su necesidad ni su desesperación privadas las que consiguen una conformación tan grande en Nietzsche; él alumbra más bien con un grito, lo que muchas generaciones han arrastrado y alimentado en sí mismas, sin que tuviesen ánimo para expresarlo. Desgarra viejos encubrimientos y vuelve a penetrar en las verdaderas dimensiones de lo humano, aunque de manera extraña, con la inmensidad y la consecuencia de su protesta atea y de su reclamo por la divinidad de la existencia. Por eso es algo imperecedero ${ }^{23}$

\subsection{Olegario González de Cardedal}

Nietzsche no consideró digno de sí a ningún otro rival que al cristianismo

O. G. de Cardedal

A diferencia de Bernhard Welte el análisis de la posición de Nietzsche frente al cristianismo en el insigne teólogo avulense se sitúa en el terreno más concreto del examen de los puntos de vista fundamentales de Nietzsche sobre el cristianismo para, a partir de ahí, ver cuáles son las contribuciones valiosas de su pensamiento para la reflexión cristiana y cuáles, por el contrario, atraviesan las líneas rojas que un cristiano, sea cual sea su orientación dentro de esta fe, no puede aceptar.

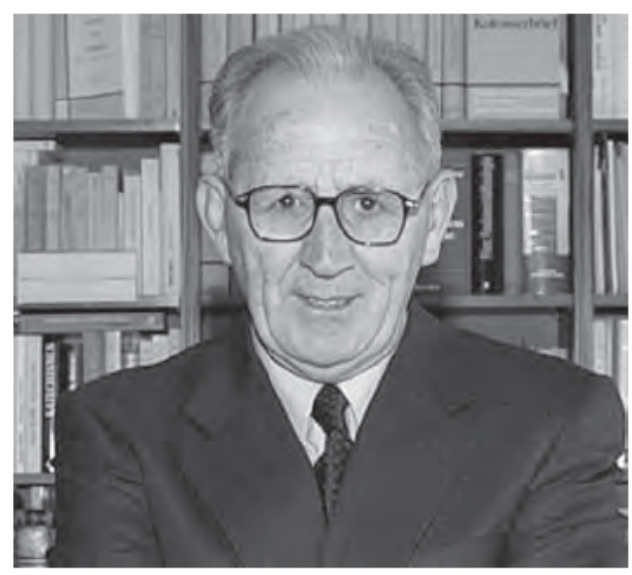

Ciertamente González de Cardedal (Lastra del Cano, Ávila, 1934) no es el único teólogo español que ha meditado sobre el filósofo alemán. Pensemos en

23. Ibíd., p. 51. 
José María Castillo o José I. González Faus. Tal interés no es de extrañar, si tenemos en cuenta que lo mejor de aquella generación de la teología española completó su formación fuera de nuestras fronteras, en ambientes teológicamente mucho más respirables, en áreas de lengua francesa y alemana; tomando allí contacto con filósofos y teólogos, católicos y protestantes, que venían pensando a fondo las consecuencias de la doctrina nietzscheana para el cristianismo.

En Cardedal no podemos esperar el entusiasmo que otra teología centroeuropea (la representada por E. Benz y otros teólogos) ha tenido hacia el filósofo alemán, pero sí es cierto que hace una valoración muy intensa, ponderada y profunda de aquellos aspectos en los que Nietzsche es incompatible de todo punto para la doctrina cristiana; y de aquellos en los que las lúcidas intuiciones del filósofo pueden servir de revulsivo para las adormecidas conciencias de muchos cristianos.

Parte el teólogo español de una constatación que -cree- recorre la obra entera del alemán: la ausencia de Dios es también la ausencia del prójimo:

Con la desaparición de Dios de su horizonte entra en crisis la metafísica y con la desaparición del prójimo entra en crisis la ética. Sin Dios y sin prójimo, el individuo queda remitido a su sola soledad 24

Es ésta sin duda una aseveración que recorre buena parte del pensamiento teológico de nuestro tiempo. Y que Cardedal, como antes De Lubac por ejemplo, tiene muy presente: certificar -como hace Nietzsche- la muerte de Dios, es certificar a su vez la defunción del hombre.

En González de Cardedal esta muerte del "hombre" se traduce en "ausencia del prójimo" en la obra de Nietzsche, quien definitivamente apuesta por una radical soledad (heroica la Ilama Cardedal). Ciertamente, es casi imposible encontrar en Nietzsche referencias a ese prójimo, a cooperaciones colectivas de los seres humanos y sí, ciertamente, apelativos continuos a la soledad de la propia tarea y a la falta de una educación para la soledad ${ }^{25}$. Si para Nietzsche Dios era el obstáculo para que viviera el superhombre, estamos ante un "punto de quiebra definitiva del prójimo y con él de la verdadera libertad y de la real esperanza en la historia moderna"26

24. O. GONZÁLEZ DE CARDEDAL, Raíz de la esperanza, Salamanca, Sígueme, 1996, p. 11.

25. "Poco a poco he ido viendo claro cuál es el defecto más general de nuestra forma de enseñar y de educar. Nadie aprende, nadie aspira, nadie enseña a soportar la soledad", NIETZSCHE, F., Aurora, \# 443.

26. GONZÁLEZ DE CARDEDAL, Raíz ..., p. 19. 
Nietzsche en el itinerario de la conciencia moderna

Como ocurre con Von Balthasar o con Martin Buber, también Cardedal cree que vivimos en la era "antropológica" 27 . Este proceso se inicia en Kant ("uno de los supremos realizadores de esa concentración antropológica en doble dirección: cognoscitiva y moral"28), continúa con Feuerbach y puede ser completado en Nietzsche.

Para el cristianismo existen tres realidades absolutamente relacionales e inseparables que, aunque tengan una autonomía particular, no pueden ser absolutizadas por separado, ni manifestar solas su esencia más íntima. Esas realidades son Dios, el Hombre, y el Mundo:

El cristianismo ha otorgado un sentimiento de infinita confianza, de infinita compañía y de infinita esperanza a la humanidad precisamente porque ha religado estas tres realidades hasta el límite de no comprender a ninguna de ellas sin las otras dos ${ }^{29}$

Por lo tanto, la ligazón de estas tres realidades es óntica y ontológica, ninguna de ellas tiene pleno sentido sin las otras dos. La Modernidad en general y Nietzsche en particular han intentado romper esa estructura:

La historia de la era moderna es la historia de abstracciones metodológicas primero, que se convierten luego en separaciones reales y terminan en negaciones finales ${ }^{30}$

Ciertamente también el cristianismo -para González de Cardedal- estuvo tentado él mismo de romper esa triple realidad:

Por momentos el cristianismo tuvo la tentación, que le contagió el platonismo y todos los dualismos que le precedieron, de pensar al hombre en relación sólo con Dios y al margen del mundo ${ }^{31}$

Y Nietzsche efectivamente quiso 'matar' una de esas tres realidades, para crear el mundo de nuevo ("yo he dividido en dos mitades la historia de la humanidad...", decía en Ecce Homo).

Nietzsche es en cierto modo un resumen de todo el pensamiento anterior y un anticipador de la tragedia del presente:

Su originalidad trágica consiste no sólo en haber pensado, sino decidido la existencia de un mundo sin Dios y de un hombre sin prójimo, de

27. Ibíd., p. 64: "La era en la que nosotros vivimos tiene al hombre como su centro: centro de interés, de valor y de finalidad".

28. Ibíd., p. 70.

29. Ibíd., p. 76.

30. Ibíd., p. 77-78.

31. Ibíd. 
los que se deducen una realidad sin origen (verdad) y una historia sin destino (esperanza). Al no existir un fundamento del mundo y una patria que espere al hombre para acogerle definitivamente, el hombre tiene que asumir el mundo sobre sus espaldas, otorgándole sentido y finalidad ${ }^{32}$

Para comprender la labor destructiva de Nietzsche, Cardedal la estructura en cuatro "destrucciones" fundamentales:

- la idea de Dios creador.

- la idea de Dios encarnado.

- la afirmación cristiana del "prójimo".

- la idea cristiana de humildad-compasión resultado de la kenosis divina.

A esas cuatro tendrá que oponer otras cuatro que Ilenen su vacío. Una deconstrucción que comienza por el lenguaje, puesto que

Nietzsche supo desde el comienzo que la palabra es la primera realidad, que el lenguaje nos precede y nos funda 33

La muerte de Dios

Esta idea clave de la filosofía de Nietzsche tiene desde luego un primer sentido "descriptivo", pero también -para Cardedal- claramente "volitivo o consumativo ${ }^{4 "}$ ". Parece difícil no coincidir con él. Es claro que, aunque Nietzsche se explaya en su primer sentido (diagnóstico-certificación de lo que ha ocurrido a la altura del XIX), y no deja de advertir los peligros que entraña (un nihilismo irreversible, si no se actúa adecuadamente), ciertamente la muerte de Dios abre para Nietzsche una posibilidad inmensa de libertad y de comienzo, como quedaba claro en el \# 343 de La gaya Ciencia:

...nos sentimos iluminados por una nueva aurora; nuestro corazón se desborda de gratitud, de asombro...

Sin duda en advertir los riesgos fue Nietzsche mucho más lúcido que sus coetáneos, puesto que

el supremo error de sus predecesores, según Nietzsche, es pensar que se puede salir de ese atolladero con un moralismo sin el fundamento religioso que ha fundamentado la moral hasta ahora ${ }^{35}$

32. Ibíd., p. 85.

33. Ibíd., p. 87.

34. Ibíd.

35. Ibíd., p. 92. 
Y en la misma línea:

La humanidad europea no conoce otra forma de vivir más que la cristiana; por ello, cuando intente vivir de otra forma sufrirá un inmenso agobio, como quien se queda sin aire para la respiración... Y contará con un siglo hasta que las sombras, que él lanzó sobre Europa, hagan primero la oscuridad total, en la seguridad de que tras ella vendrá la nueva luz total ${ }^{36}$

El nihilismo generalizado está ocurriendo, aunque el propósito de Nietzsche fuera superarlo. Él puede ser considerado su "consumador", pero Cardedal enumera hasta siete co-causantes del nihilismo: la Escolástica filosófica, Lutero, Descartes y Kant, los olvidos de la teología, el deísmo, la Ciencia e incluso una Iglesia "acosada y cuestionada". Es en este transfondo donde la reacción de Nietzsche debe ser comprendida ${ }^{37}$.

Las aportaciones de Nietzsche útiles para el cristianismo

Nada mejor que la siguiente cita de su obra Raíz de la Esperanza para advertir ese difícil equilibrio que para el cristiano supone tener que aceptar tanto como rechazar de Nietzsche:

Un cristianismo trasvalorado en mera moral, con ley y sin gracia, es lo más des-graciado que pensarse pueda [...] Hay en Nietzsche ciertos atisbos de mística verdadera (El Dios real frente al Dios moral; el Dios vida frente al Dios concepto; el Dios infinitud frente al Dios historia; el Dios que integra al hombre en su poder y ser frente a la pura relación externa...) que quedan pulverizados y desnaturalizados en la violencia de su odio frente a Dios y de su envidia a Jesucristo ${ }^{38}$.

Un importante artículo del teólogo avulense, "Dioniso contra el Crucificado. La Fe en Cristo después de Nietzsche" ${ }^{39}$, nos sirve como referencia para fijar aquellos aspectos del pensamiento nietzscheano que tienen una importancia fundamental para la religión cristiana. Él habla de las tres formas básicas que los

36. Ibíd., p. 101.

37. Ibid., p. 103:"El símbolo de esta ambigüedad son para Nietzsche el protestantismo y Kant, como radicalizadores de los imperativos morales, tras privarles de sustancia y fundamento religioso. Aquí es donde se revela la inmensa lucidez de su pensamiento al rechazar lo que él llama el 'Dios moral', con el mantenimiento de la exigencia una vez que se ha olvidado la gracia. Nietzsche tiene razón contra Kant" [En la nota al pie, no 55, pág. 103, González de Cardedal hace un comentario sobre una obra anterior, Ética y Religión, Madrid, 1977, pág, 325, donde reconoce su propia evolución en relación con Nietzsche.

38. Ibid., p. 104.

39. O. GONZÁLEZ DE CARDEDAL, "Dioniso contra el Crucificado. La Fe en Cristo después de Nietzsche", Artículo en la Revista Teología 80, año 2002, p. 11-52. 
diferentes pensadores cristianos han tenido de reaccionar ante sus provocativas afirmaciones:

- Aquellos que lo han rechazado sin real reflexión.

- Quienes han sentido una fascinación entusiasta -que él no compartecomo si Nietzsche hubiera venido a regenerar el cristianismo.

- La postura más cabal de quien toma una "distancia serena" y acepta parte de sus críticas y toma severa distancia y rechazo de otras, especialmente su insensibilidad para "esas dimensiones sagradas de la vida humana que son la compasión y la solidaridad con el prójimo".

Como tantos otros, no deja de señalar el teólogo español la ambigüedad casi irresoluble de Nietzsche hacia Jesús, sobre quien alterna juicios muy críticos con otros donde lo considera un "espíritu libre", "noble" y a quien siempre exonera de cualquier responsabilidad en la deriva del cristianismo.

Pero la gran tragedia de Nietzsche para González de Cardedal es haber pensado un universo donde el Amor está ausente, donde el mismo Nietzsche es incapaz de amar y de reconocerse en su prójimo. En su raíz biográfica, en su falta de amor vital y en su actitud ante la mujer, ve Cardedal muchas razones explicativas de su filosofía. Junto a ellas, falta en Nietzsche una verdadera consideración sobre el asunto de la muerte

¿Cómo es posible que haya olvidado un hecho determinante de toda la existencia: la muerte? ¿Que la haya volatilizado con ese fácil recurso al amor fati por un lado y a la idea del eterno retorno por otro? ${ }^{40}$

Nietzsche nunca comprendió realmente lo que significó el hecho de la Cruz y la interpretó completamente al revés en La genealogía de la moral, como instrumento de la venganza y el resentimiento judío:

La cruz no es el instrumento del miedo, de la venganza o del castigo futuro sino del Amor que padece y compadece, que desde dentro asume y supera. Nietzsche, con aquella lucidez que a veces el odio engendra, vio que esa cruz implicaba una trasvaloración de todos los ideales y esperanzas del mundo en medio del que estuvo plantada. Los judíos esperaban justificarse ante Dios por el cumplimiento de la ley y los griegos desvelar el último sentido por la conquista de la sabiduría. Ambos partían del convencimiento de que el Absoluto es la distancia y que el camino va de abajo hacia arriba. Ninguno pensó que el camino del Absoluto divino y de la salvación humana podía ir de arriba hacia abajo ${ }^{41}$

40. Ibíd., p. 24.

41. Ibíd., p. 30-31. 
Pero este distanciamiento no le impide encontrar hallazgos filosóficos de gran valor en el pensamiento de Nietzsche sobre el cristianismo. Sus propias palabras son clarificadoras:

Nietzsche ha prestado un servicio impagable al cristianismo. Por su rechazo agresivo nos ha hecho asombrarnos de nuevo ante la escandalosa novedad del Dios cristiano. Su odio ha sido a veces casi tan clarividente como nuestro amor: ninguno de nosotros nos hubiéramos atrevido a pensar un Dios crucificado.

\section{[...]}

Nietzsche rechazaba lo que él Ilama "un Dios moral". Quizá estemos aquí ante una de las canteras más ricas del pensamiento de Nietzsche. El ha querido diferenciar primero y separar después Dios y la moral. Y con toda razón ha desenmascarado una cierta tradición occidental que ha antepuesto la moral a Dios, haciendo de éste el presupuesto o el legitimador, recompensador y ratificador de una moral, que en el fondo funcionaba con plena autonomía, derivada de factores sociales, psicológicos o políticos. Dios quedaba así enclavado y esclavizado por la moral. Los hombres reaccionaron contra Dios, cuando se tenían que rebelar contra esa moral. Con razón se han repetido las dos frases de Nietzsche en las que afirma en un caso y pregunta en otro por la relación entre moral y Dios.

“En el fondo es sólo el Dios moral el que está superado. ¿Tiene sentido pensar en un Dios más allá del Bien y del mal?"42.

Nietzsche ha sido así quien ha visto más profundamente fuera del ámbito religioso los peligros y las consecuencias que para el cristianismo -y para la forma de ejercer el sacerdocio- ha tenido la confusión de religión y moral:

Agradecimiento merece Nietzsche por sus análisis psicológicos de cierta ejercitación moral en la iglesia, de alguna forma de ser sacerdotes y de las instituciones que distribuyen los signos de la gracia, en la medida en que esos comportamientos revelan la secreta envidia del acomplejado, el rencor del incapaz de amar lo que le excede, el desprecio de lo bello y lo sublime cuando nos es inalcanzable, la incapacidad de alegrarse con el bien del prójimo, la voluntad de reducirlo todo a los propios límites, la depreciación del tiempo y del mundo por una reducción o sometimiento ilegítimos a la eternidad ${ }^{43}$.

42. Citado en "Dioniso contra...", p. 32.

43. Ibíd., p. 34-35. 
Hasta cierto punto ha resultado fácil para Nietzsche cargar contra una cierta y poderosa tradición de ejercicio del cristianismo que ha vilipendiado el mundo y todo lo creado y contingente pero, para Cardedal, es ésta una interpretación sesgada de la religión cristiana, puesto que

todas las retóricas que han vilipendiado la creación para engrandecer la obra divina son anticristianas ${ }^{44}$.

Aquí se encuentra el teólogo español en la misma tesis que defendía el teólogo Wolfgang Pannenberg: la necesidad de devolver la sacralidad a la vida y a la existencia humanas en este mundo debe ser obligación absoluta del cristianismo, y no otra era la misión de Zaratustra ${ }^{45}$.

Evidentemente para Cardedal de la encarnación se deriva un amor absoluto por la realidad carnal y temporal en que existimos. Para él ningún maniqueísmo o dualismo es conciliable con la fe cristiana.

Tal vez Nietzsche sólo conoció la fórmula y la línea más rigorista del cristianismo, la que acentuó la culpa, la que ve al hombre bajo la luz del pecado, de la corporalidad venal y en Cristo la necesaria justificación, expiación y reconciliación con el hombre. Es la línea de Pablo, Agustín o Lutero, entre otros. Pero, ¿qué ocurre con el otro cristianismo, el del Evangelio de Juan, Ireneo, Orígenes, Santo Tomás, Erasmo, la mística castellana, Blondel, Rahner?

Finalmente, y a pesar de que muchos teólogos de su generación y anteriores vieron una esperanza y una positividad en Nietzsche para la recuperación de un cristianismo diferente, con otro nervio y más uncido a lo real y al hombre concreto $^{46}$, Olegario González de Cardedal no puede ser tan optimista con el pensador alemán, a pesar de reconocerle importantes méritos, pues le reprocha haber sido radicalmente injusto y no comprender la esencia de esta religión. No obstante quede esta cita final como testimonio de su agradecimiento al pensador alemán:

Nietzsche ha sido una provocación y un revulsivo para el cristianismo. Comprendemos lo que quiere decir y aprobamos no pocas cosas que quiere superar. Como pocos ha diagnosticado ciertas patologías de lo

44. Ibíd., p. 36.

45. PANNENBERG W., Una historia de la filosofía desde la idea de Dios, Salamanca, Sígueme, 2001.

46. Así nos recuerda Cardedal esta cita de Biser: "Detrás de esta lucha a muerte contra el cristianismo yacería a manera de escritura en palimpsesto su admiración por Cristo, una voluntad de hacerle revivir en sus mejores intenciones y una voluntad de retrotraerse más allá del cristianismo histórico hasta otro, en un sentido originario de Jesús y en otro sentido nuevo". BISER, E., Nietzsche y la destrucción de la conciencia cristiana, Salamanca, Sígueme, 1974. p. 46. 
cristiano. Ha vivido deslumbrado ante el esplendor de la realidad y nos ha invitado a estar en cada instante y lugar, como en el cenit de la luz, gozosamente implantados como quienes son el centro de la realidad y de la historia ${ }^{47}$.

\section{Gianni Vattimo: la muerte de Dios como oportunidad para el cristia- nismo}

También algunos filósofos, entre la pléyade de quienes han venido reflexionando sobre Nietzsche desde el pasado siglo, han insistido en interpretar las opiniones de éste en torno a la religión cristiana y a su diagnóstico de la muerte de Dios, desde una perspectiva que no sólo no resulta destructora del cristianismo, sino que, por el contrario, puede servir para una revitalización depuradora de éste.

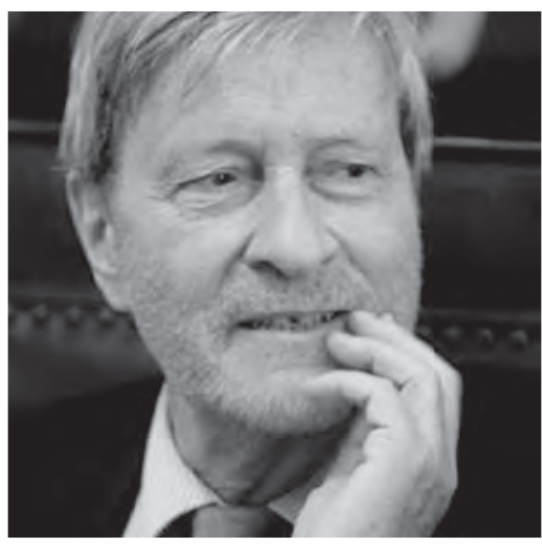

Es el caso del filósofo italiano Gianni Vattimo (Turín, 1936), quien se ha ocupado de Nietzsche en multitud de libros y artículos. Muy ligado también al pensamiento de Heidegger, mantiene la tesis de que el único "Dios" de quien el filósofo alemán anuncia la desaparición es el Dios de la metafísica. Dios, que en su caída arrastra tras de sí la ruina de la tradición del pensamiento fuerte de Occidente, anclado desde siglos en las categorías parmenídeas y aristotélicas del ser. Como resultado de tal limpieza puede emerger una vivencia religiosa no dogmática a la que Nietzsche, involuntariamente, habría contribuido a liberar.

Las dos muertes de Dios

En realidad la muerte de Dios no sucede una, sino dos veces. La primera es el sacrificio de Jesús en la cruz, símbolo sublime para Vattimo de la Kenosis, "rebajamiento" de Dios al estatuto humano; la segunda es la muerte del Dios de la metafísica, del Dios moral. Recurre el profesor italiano al tantas veces citado fragmento póstumo: "En el fondo es sólo el Dios moral el que está superado". Nietzsche no dejará nunca de desear que haya dioses, o, mejor, que los hombres se conviertan en dioses.

47. Ibíd., p. 41. 
Ni siquiera la expresión "muerte de Dios" es originalmente nietzscheana, como nos recordaba Henri de Lubac $^{48}$. La primera muerte es evidentemente la del profeta de Nazaret en la cruz, en el primer siglo de nuestra era. La interpretación que Vattimo y otros filósofos hacen de este acontecimiento, que naturalmente resultará forzada para la exégesis tradicional, aporta luces muy interesantes para la ubicación del concepto nietzscheano de la muerte de Dios.

Intentando ser sintéticos, esa primera vida y muerte de Jesús significa:

- Toda una hermenéutica, un "desciframiento", del Antiguo Testamento (en la línea paulina), el cumplimiento y la superación de la Ley y los profetas.

- La aceptación de las tesis de René Girard ${ }^{49}$ : el sacrifico de Jesús y, antes, su actitud, vienen a clausurar la vieja relación de lo sagrado con la violencia, a denunciar la persecución de las víctimas, que todas las religiones han profesado. Por tanto, Jesús procede a inaugurar una nueva era de relación del hombre con la divinidad.

- El inicio, por decirlo así, del proceso histórico de la secularización. La afirmación rotunda -para Vattimo- de que el proceso nace de las mismas entrañas del cristianismo: "Occidente es cristianismo secularizado". La demostración de estas tesis, que expresamente remite el autor a los trabajos de Max Weber, pueden estar condensada en esta afirmación:

¿Qué son, de hecho, Europa u Occidente, o la modernidad si no, ante todo, civilización de la racionalidad científica, y económica, y tecnológica? Pero esta racionalidad, como nos enseñó Max Weber, y ahora ya se ha repetido hasta la saciedad, no se ha realizado en ninguna otra cultura del planeta, ni siquiera cuando se daban todas las demás condiciones materiales, porque sólo en Occidente actuaba la tradición religiosa judeocristiana. El monoteísmo (resumo aquí de manera rápida y tosca) es la condición para pensar la naturaleza bajo la perspectiva unitaria de la ciencia física, base indispensable del dominio de la naturaleza; la ética cristiana, sobre todo protestante, es la condición para concebir el trabajo, el ahorro, el éxito económico, como imperativos religiosos y, por lo tanto, capaces de suscitar un compromiso profundo y total ${ }^{50}$.

La muerte de Dios en el sentido revelado por Nietzsche no es el final de la religión, ni el deseo de que desaparezca la religión de la faz de la tierra. Esto parece una afirmación temeraria respecto a alguien que se ha denominado a sí mismo anticristo y que ha lanzado su maldición sobre el cristianismo. Sin embargo -estamos de acuerdo con Vattimo- hay poderosas razones para pensar así.

48. LUBAC H., El drama del Humanismo ateo, p.35-36

49. GIRARD R., Veo a Satán caer como el relámpago, Barcelona, Anagrama, 2002.

50. VATTIMO G., Después de la Cristiandad. Por un cristianismo no religioso, p. 96. 
"Que Dios ha muerto significa para Nietzsche que no hay fundamento último, y nada más $s^{51 " . ~ V a t t i m o ~ r e l a c i o n a ~ e s t e ~ c o n c e p t o, ~ y ~ e l ~ d e ~ l a ~ c r i ́ t i c a ~ a ~ l a ~ c o n c e p c i o ́ n ~}$ de la metafísica tradicional por Heidegger, como una referencia significativa y especialmente lúcida de un proceso común al pensamiento de las primeras décadas del siglo XX, pero que hunde sus raíces también en el nacimiento de las ciencias humanas en el XIX. Significaría la crítica de una cultura objetivista y racionalizadora, ligada a la manera de pensar del mundo occidental y a la consideración de Occidente, de Europa, como la culminación de todas las formas de comunidad humanas. La época que vivimos hoy -fruto de esa reevaluación crítica de nosotros mismos- es denominada por Vattimo "postmoderna".

También, entre otros trastornos, la negación nietzscheana del "fundamento último" hace posible que desaparezca la necesidad del ateísmo filosófico ${ }^{52}$. Tal imperativo de negación sería una suerte nueva del viejo absolutismo y, por tanto, es absurdo negar hoy a los ciudadanos el derecho a la vivencia religiosa.

Pero las consecuencias de la negación de la metafísica, es decir, de una verdad objetiva y fundamental en la raíz de las cosas, son más amplias. Si desaparece la noción de una estructura única y fija del ser, sólo queda una visión de lo real como "contingencia" o "historicidad". Por tanto, hemos de recibir los mensajes de la religión, pero también los procedentes de las ciencias, como propuestas (en términos de Vattimo, tomar conciencia de la historicidad de sus paradigmas).

Yendo un paso más allá, el filósofo italiano piensa que es precisamente la tradición judeocristiana ("que piensa lo real como creación y como historia de la salvación") la que permite a ese pensamiento postmoderno liberarse de la metafísica objetivista y del cientificismo dominante ${ }^{53}$.

De vuelta al terreno de la religión, el rostro de Dios que nos aparece, una vez despojado de su piel moral, es decir, de la epidermis metafísica, resulta muy diferente al que la tradición escolástica había enseñado durante siglos: construcción religiosa que recubre la metafísica griega, y que la Iglesia romana, renuente a esta renuncia, aún enseña. Asumir a un Dios en estas condiciones, un Dios, o, si se quiere, un Reino, en permanente construcción por una comunidad de creyentes unida por la piedad, el amor y la amistad es ciertamente duro para la visión tradicional. Sin embargo, tal vez a Nietzsche le parecería más fácil de aceptar, puesto que "no podría creer en un Dios que no supiera bailar", decía Zaratustra. ¿Pero acaso el Hijo del Hombre no participaba en bodas y las alegraba, no participaba de los pequeños placeres a disposición de los hombres, no los defendía frente a los severos moralistas de su tiempo ${ }^{54}$ ?

51. Ibíd., p. 11.

52. Ibíd., p. 13.

53. Ibíd., p. 16.

54. Lc 7, 34: "Ha venido el Hijo del Hombre, que come y bebe, y decís: "Mirad, un hombre glotón y bebedor de vino, amigo de recaudadores de impuestos y de pecadores". 
En los términos en los que la interpreta Vattimo, y aproximándola siempre con el fin de la metafísica anunciado por Heidegger (la devolución al "ser" de lo que le había usurpado el "ente"), la muerte de Dios significa que:

La creencia en Dios ha sido un poderoso factor de racionalización y disciplina, que ha permitido al hombre salir de la selva primitiva del beIlum omnium contra omnes, y ha favorecido también la constitución de la visión "científica" del mundo que abre el camino a la técnica cuyos efectos son asegurar y facilitar la existencia ${ }^{55}$.

Con esta toma de postura, desde luego lo tienen complicado quienes persistan en una interpretación de Nietszche radicalmente enemigo de la religión y la moral: no sólo -afirma Vattimo- la religión nos ha sacado del "estado de naturaleza", sino que ha hecho posible la racionalización científica moderna e incluso ha proporcionado a los fieles los instrumentos para su propia superación, en forma de una voluntad de veracidad a toda costa.

Siguiendo las tesis de Vattimo parece absurdo pensar que Nietzsche está proponiendo un ateísmo como verdad objetiva de la existencia, cuando tal actitud sería una recaída en la metafísica más dogmática. Si está proponiendo una divinización del hombre, no debería sonarnos tan herético, cuando un acontecimiento tal ocurrió al principio de la historia de la salvación, como dice Pablo:

Haya, pues, en vosotros este sentir que hubo también en Cristo Jesús, el cual, siendo en forma de Dios, no estimó el ser igual a Dios como cosa a que aferrarse, sino que se despojó a sí mismo, tomando forma de siervo, hecho semejante a los hombres ${ }^{56}$.

La disolución de la metafísica (otra manera de expresar en términos de Heidegger el fin del "Dios moral") se demuestra en la profunda implosión de las sociedades modernas: la multiplicación de los lenguajes científicos, la pluralidad de las conformaciones morales de los individuos, la multiplicidad moral y religiosa que ahora se mira a la cara y convive en los espacios europeos y, desde luego, la caída en descrédito de todos los grandes relatos de interpretación histórica (de la izquierda a la derecha), son la expresión pública de esos conceptos de ambos filósofos alemanes. Es ahora - a pesar de la preocupación comprensible de muchos sectores de la Iglesia institucional-cuando "parece haber muchos indicios de que justamente la muerte de este Dios ha liberado el terreno para una renovada vitalidad de la religión". ¿Por qué?

En primer lugar, y por razones ya señaladas, se ha hecho absurdo perpetuarse en las bases filosóficas tradicionales del ateísmo. En alguna medida-comenta

55. VATTIMO G., Después de la cristiandad..., p. 22.

56. Filipenses 2, 5-7. 
Vattimo- esto ha venido a hacer realidad el intento de Kant de separar el problema de la existencia de Dios del ámbito de la razón teórica y re-conducirlo a la dimensión de la razón práctica.

Igualmente, y este es un sentido en el que había insistido Nietzsche desde sus obras más tempranas, porque el final de un solo discurso (lenguaje) verdadero, hace devolver a la palabra su original significación de metáfora y des-jerarquizar la pluralidad de lenguajes (sin duda el lenguaje religioso ha sido uno de los más devaluados por el lenguaje de la razón instrumental dominante, que lo ha considerado a menudo como 'infantil', 'consolador' y en cualquier caso 'i-racional').

Otra razón, decisiva, con potencialidades positivas pero también peligrosas, tiene que ver con el hecho de que las religiones y las morales conviven en el seno de las mismas ciudades de Europa, antes recorridas por la uniformidad. Elementos positivos de esa horizontalización de las religiones son los intentos, unos más felices que otros, impulsados por el poder católico romano, de dialogar con los otros credos del monoteísmo sin imposiciones ni superioridades; diálogo fecundo y necesario que debe proseguir. Mas, lo señala el filósofo italiano, es evidente para cualquiera que también esta visibilidad recíproca de las religiones conlleva reacciones defensivas, de tribu, que fortalecen los elementos más montaraces y hostiles hacia el otro.

Los aspectos potencialmente positivos de esta liberación de las estructuras fuertes y dogmáticas de la metafísica tradicional no pueden hacernos olvidar los peligros inherentes a la misma: la posibilidad de creer y otorgar a todas las actitudes vitales, a todas las morales y a todas las cosmovisiones y discursos el mismo valor o ningún valor. Este es uno de los peligros que Nietzsche acertaba a ver en el nihilismo que se avecinaba. En su propuesta, como ya supo ver Albert Camus en El hombre rebelde, se imponía una tarea que era cualquier cosa menos a-moral y exenta de sacrificios: educar al hombre para hacerse cargo de manera adulta de la conducción de la vida. El peligro, que apunta Vattimo, es la posibilidad, que muestra signos preocupantes en nuestras sociedades, de caer en la 'barra libre' en los asuntos éticos. Recurriendo a la idea heideggeriana de que el ser no es 'ente' pero es 'acontecimiento', 'horizonte', hay que bucear en la historia del ser, y la historia del ser es la tradición de todas sus encarnaciones y formas históricas, también las religiosas. El cristianismo, aunque acepte todas las devaluaciones posibles de su concepción de Dios y de las morales normativas que lo han acompañado históricamente, no puede, sin embargo, sino atrincherarse en la norma infranqueable que constituye su esencia incontrovertible, el "amor al prójimo", la caritas; dicho de otro modo, el reconocimiento del valor absoluto, sagrado, del otro, y el respeto que se le debe (como a uno mismo). Es el límite último no sólo para que el cristianismo viva, sino incluso para que pueda darse una sociedad decente. 


\section{La secularización}

El término "secularización" ha sido el que ha tenido un éxito más notable para definir el proceso de 'retirada' de lo sagrado y la progresión de los valores de la laicidad, en la misma dirección en que se desarrollaban las ciencias, las técnicas y el Estado moderno. La tesis que plantea Vattimo, todavía provocativa para sectores cristianos tradicionales, es considerar el carácter, el origen, fundamentalmente interno al desenvolvimiento del propio cristianismo de este proceso. Con lo cual nos encontramos en la misma línea expresada por Nietzsche en cuanto que la muerte de Dios es sólo fruto de la lógica del cristianismo y del ideal ascético, Ilevados a sus últimas consecuencias. Lo que Vattimo pretende demostrarnos, recurriendo a la figura de Joaquín de Fiore, es que quien muere con el advenimiento de la Modernidad es fundamentalmente el Dios del Antiguo Testamento. Un proceso conocido como 'disolución de la trascendencia', conceptualmente muy cercano al de "muerte de Dios" y que se iniciaría con la encarnación /muerte/salvación de Jesús. Es evidente que la tradición dominante en el cristianismo no ha aceptado, ni tampoco hoy aceptaría, las consecuencias más radicales de lo que Pablo Ilamaba kenosis o "rebajamiento" de Dios al hombre, al esclavo. Lo que quiere decir que la Iglesia -ejecutora también de la práctica caritativa de Jesús de Nazaret- ha permanecido "fiel" al modelo de Dios-Padre del Antiguo Testamento, que no es sino el Dios moral (Décálogo) o el Dios de la metafísica. Y si la tradición católica no ha podido desprenderse de esta concepción de Dios (tapagujeros, decía Bonhoeffer), en absoluto lo ha hecho el protestantismo con su obsesión por el apego absoluto al Libro, como única fuente de verdad ("sola Scriptura") como nos recuerda Vattimo citando a Novalis ${ }^{57}$. Lo cual nos remite a lo que Paul Valadier nos recordaba de la radical crítica que Nietzsche hacía de la fijación de la Verdad y de Dios en un libro, frente a las reticencias de Jesús hacia todo lo fijo ${ }^{58}$.

Pero el carácter histórico de la salvación no quiere decir ni más ni menos que la realización plena del proyecto cristiano, inaugurado por Jesús, se materializará en el tiempo de los hombres y en la vida humana de los mortales y no en forma de resurrección en una existencia superior. Y la salvación del hombre en la historia es precisamente el proyecto vital de Nietzsche: la concreción de la salvación es un acontecimiento que se produce en el tiempo histórico. Si Nietzsche hubiera creído que esta formalización de la salvación en la historia era el proyecto dominante del cristianismo, el terreno del entendimiento mutuo entre ambos se hubiera agrandado hasta límites insospechables.

¿En qué sentido la muerte de Dios puede hacer resurgir una vivencia más auténtica del cristianismo que la que históricamente ha sido posible?

57. VATTIMO G., Después de la cristiandad, p. 47.

58. VALADIER P., Nietzsche y la crítica del cristianismo, Madrid, Cristiandad, 1982. 
En primer lugar, porque el cristianismo ha podido inspirar la construcción, desde luego aún muy imperfecta, del orden secular:

Sería difícil pensar la evolución de las formas políticas modernas en sentido democrático sin la concepción cristiana de la fraternidad de los hombres, hijos de un único Dios. El repudio de la guerra -al menos teóricamente- por parte de la Carta de la ONU también es, ciertamente, un efecto de la acción profunda de las ideas cristianas o, en un sentido más amplio, religiosas ${ }^{59}$

Finalmente, porque permite al cristianismo descubrir la única cosa necesaria, lo único que de verdad cuenta como criterio absoluto: su concepto de "caridad". Profundizando más, la intelección de la historia del ser como debilitamiento, en el sentido comentado que se inicia con la kenosis de Dios en el hombre puede, ahora sí, retomar la voluntad inaugural del cristianismo: la abolición de toda violencia entre los hombres y la exclusión mutua de los términos que venían unidos desde tiempo inmemorial: religión y violencia. Esto es lo que debe hacer posible la práctica de una tolerancia activa entre hombres y creencias. Tarea clara, pero en absoluto fácil en opinión de Vattimo.

\section{En conclusión}

Hemos podido ver, a través de tres autores "cristianos" de características y generaciones tan distintas como Welte, González de Cardedal y Vattimo, cómo las posibilidades de pensar a Nietzsche desde el cristianismo distan de estar agotadas. Ciertamente sus acercamientos ahondan en aspectos muy diversos de la obra del pensador alemán: Welte en la intuición de que en el fondo del pensamiento de Nietzsche late la misma pasión por la "unidad" de lo existente y la reconciliación final en un todo afirmativo; la misma aspiración de cada hombre a su "salvación" suprema, sea concebida ésta a la manera de una re-ligación del sufriente yo en una unidad superior y afirmativa -que las religiones han Ilamado "Dios", -o bien sea entendida a la manera unamuniana de "supervivencia del yo personal"-.

González de Cardedal ha centrado su polémica con Nietzsche en otros aspectos, reconociendo que la distinción nietzscheana de moral y religión, y la progresiva absorción histórica de ésta por aquélla, ha hecho mucho daño al cristianismo. Ha reconocido en Nietzsche un indirecto revitalizador de una fe que todavía no ha sabido sacar -salvo casos como los de Jurgën Moltmann ${ }^{60}$ - las ra-

59. VATTIMO G., Después de la cristiandad, p. 60-61.

60. "Jesús murió gritando a Dios: "Dios mío, Dios mío, ipor qué me has abandonado?" Toda teología y toda existencia cristianas responden, en realidad, a esta pregunta de Jesús. También el ateísmo de las protestas y las rebeliones metafísicas contra Dios responde a esta pregunta". J. Moltmann, El Dios crucificado, Sígueme, p. 13. 
dicales consecuencia del escándalo que supone un Dios crucificado y, finalmente, también ha vuelto a afirmar algo muy nietzscheano, que siglos de desvaloración cristiana del mundo fenoménico habían olvidado: que este mundo, el mundo de la Creación y del Hombre, del espíritu pero también de la materia, del alma pero también del cuerpo, fue considerado "bueno" por Dios mismo (Génesis 1, 31) y por tanto (citamos una vez más): "todas las retóricas que han vilipendiado la creación para engrandecer la obra divina son anticristianas".

Vattimo ha situado el problema en torno a la cuestión de la "muerte de Dios" $y$, como hemos visto, desde posiciones que hacen coincidir la tesis nietzscheana con la del "final de la metafísica" de Heidegger, afirma que para el cristianismo -entendido como comunidad de creyentes que construyen y comparten una "fe" que es fundamentalmente, una praxis, una ética de la caritas-, la muerte del Dios de la metafísica, la muerte del Dios enmarañado por siglos de conceptos, gnosis y polémicas conciliares, más que un problema quizá suponía la oportunidad de re-vitalizar un cristianismo para que se vuelque en su verdadero horizonte "samaritano": hacia el hombre concreto, sufriente, y golpeado por estructuras de injusticia hoy más activas que nunca.

Han sido tres ejemplos, muy notables ciertamente, pero hubiéramos podido recoger muchos más -tanto desde el ámbito teológico -católico y protestantecomo desde la propia filosofía. Por ejemplo, no olvidamos que muchos intelectuales católicos franceses del entorno del Personalismo recibieron con interés muchas propuestas del anticristo Nietzsche. Si hubiéramos añadido algún teólogo español más de la propia generación de Cardedal -como los casos de José María Castillo o J. I. González Faus- advertiríamos también la presencia y el acomodo que algunas ideas del pensador alemán tienen en su pensamiento.

Ello nos invita a pensar la razón que tenía Wolfgang Pannenberg cuando afirmaba que "la recepción de Nietzsche se halla todavía en sus comienzos"61. Aunque, ciertamente, también hemos de confesar ciertas dudas o temores: ¿No parece, acaso, que el pensamiento cristiano en el momento presente carece de aquella potencia y receptividad desprejuiciadas con las que se comunicó con la no-creencia en las décadas anteriores y en los años que sucedieron al Concilio Vaticano II? ¿No fue aquel contexto especial y el hecho de luchar codo con codo ateos y cristianos contra el Mal, como lo hicieron en las décadas centrales del siglo XX, no tuvo acaso el feliz efecto colateral de reconocerse mutuamente también en el plano filosófico, como proyectos no excluyentes de liberación del hombre?

61. PANNENBERG W., Una historia de la filosofía desde la idea de Dios.

62. NIETZSCHE F., Así habló Zaratustra, 1a Parte, Prólogo, IV. 
Queremos afirmar, finalmente, dos cosas: que el espacio de interacción entre Nietzsche y el pensamiento cristiano sigue polémicamente vivo y que no hay ningún motivo para restringir los límites de la filosofía nietzscheana a una mera discusión especializada de eruditos y académicos; pues, si algo (a pesar de su elitismo) tenía claro el alter ego de Nietzsche, el eremita Zaratustra, es que hablaba 'para todos y para nadie', y que a quienes realmente él amaba y consideraba dignos de heredar la Tierra eran

quienes viven para el conocimiento y tratan de saber, para que algún día llegue a existir el superhombre

quienes justifican a los hombres del futuro y redimen a los del pasado, pues quieren perecer a causa de los hombres del presente ${ }^{62}$

\section{Bibliografía fundamental}

GONZÁlEZ DE CARDEDAL, O., Raíz de la Esperanza, Salamanca, Sígueme, 1997.

GONZÁLEZ DE CARDEDAL, O., "Dioniso contra el Crucificado. La Fe en Cristo después de Nietzsche", en Teología, nº 80. Tomo XXXIX. Año 2002, pp. 11-52. Buenos Aires (Argentina).

NIETZSCHE, F., Obras.

VATTIMO, G., Creer que se cree, Barcelona Paidós, 1997.

VATTIMO, G., Introducción a Nietzsche, Barcelona, Península, 2001.

VATTIMO, G., Después de la Cristiandad. Por un cristianismo no religioso, Barcelona, Paidós, 2003.

WELTE, B., El ateísmo de Nietzsche y el Cristianismo, Madrid, Taurus, 1962. 